\title{
Growth, cell division and sporulation in mycobacteria
}

\author{
Bhupender Singh • Jaydip Ghosh • Nurul M. Islam • \\ Santanu Dasgupta $\cdot$ Leif A. Kirsebom
}

Received: 14 December 2009/Accepted: 13 April 2010/Published online: 1 May 2010

(C) The Author(s) 2010. This article is published with open access at Springerlink.com

\begin{abstract}
Bacteria have the ability to adapt to different growth conditions and to survive in various environments. They have also the capacity to enter into dormant states and some bacteria form spores when exposed to stresses such as starvation and oxygen deprivation. Sporulation has been demonstrated in a number of different bacteria but Mycobacterium spp. have been considered to be non-sporulating bacteria. We recently provided evidence that Mycobacterium marinum and likely also Mycobacterium bovis bacillus Calmette-Guérin can form spores. Mycobacterial spores were detected in old cultures and our findings suggest that sporulation might be an adaptation of lifestyle for mycobacteria under stress. Here we will discuss our current understanding of growth, cell division, and sporulation in mycobacteria.
\end{abstract}

B. Singh $\cdot$ N. M. Islam - S. Dasgupta

L. A. Kirsebom $(\square)$

Department of Cell and Molecular Biology, Biomedical Centre, Uppsala University, Box 596, 75124 Uppsala,

Sweden

e-mail: leif.kirsebom@icm.uu.se

J. Ghosh

Institut National de la Santé et de la Recherche Médicale U869, ARNA, IFR Pathologies Infectieuses et Cancers, Université Victor Segalen, 146 Rue Léo Saignat, 33076 Bordeaux, France
Keywords Mycobacteria - Bacterial cell division · Septum formation $\cdot$ Sporulation

\section{Introduction}

Mycobacterium

Bacteria of the genus Mycobacterium are acid fast, show a great resilience against environmental insults and they inhabit various environmental reservoirs e.g. ground and tap water, soil, animals and humans. They are grouped among the actinomycetes and include nonpathogens as well as highly successful pathogens e.g. Mycobacterium tuberculosis, Mycobacterium leprae and Mycobacterium ulcerans, the etiological agents of tuberculosis (TB; 10 million new cases per year develop active disease), leprosy and Buruli ulcer (the third most common mycobacterium infection), respectively (see e.g. Sasaki et al. 2001; Russell 2007; Demangel et al. 2009). While M. tuberculosis is human-specific, the closely related Mycobacterium bovis can infect both humans and animals and lead to TB regardless of host. Another Mycobacterium is the multihost chronic enteric pathogen Mycobacterium avium subsp. paratuberculosis (MAP) that causes chronic diarrhea among ruminants (Johne's disease). It can be present in food products derived from cattle (Chacon et al. 2004) and some data suggest that MAP is the causative agent of Crohn's disease in humans 
(see e.g. Greenstein 2003; Uzoigwe et al. 2007). Mycobacteria are also commonly present in water, e.g. Mycobacterium avium and M. ulcerans, and hence they can constitute a threat to both animals and humans. Interestingly it appears that mycobacteria have a growth advantage in water that contains disinfecting agents e.g. chlorine (Vaerewijck et al. 2005; Primm et al. 2004). Moreover, Mycobacterium marinum causes a systemic TB-like infection and disease in ectothermic hosts e.g. fish and frogs. In comparison to $M$. tuberculosis, M. marinum grows with a relatively short doubling time and growth is limited at higher temperatures, making M. marinum easier to handle than e.g. M. tuberculosis and study in the laboratory. M. marinum has therefore become a model system to identify and study factors important for mycobacterial infections, disease development and its persistence (Ramakrishnan 2004).

Mycobacteria can grow in fluid environments, they can form aggregates, form biofilms and they are invasive i.e. they can grow and multiply within cells such as macrophages. Inside the macrophage they reside within a membrane-bound cytoplasmic vacuole referred to as the Mycobacterium phagosome. Pathogenic mycobacteria such as M. tuberculosis avoid phagolysosomal degradation by: (i) blocking acidification of the phagosome, (ii) altering the protein content of the vacuole and (iii) preventing interactions with other endosomal compartments. This ensures survival of the bacteria within the macrophage and subsequent spread of the pathogen to other cells e.g. dendritic cells and neutrophiles (Wayne and Sohaskey 2001; Glickman and Jacobs Jr 2001; Flynn and Chan 2003, 2005; Deretic et al. 2004; Nguyen and Pieters 2005; Vergne et al. 2004; Ojha et al. 2005; Carter et al. 2003).

Mycobacterium tuberculosis and other mycobacteria can also establish long-term infections that lead to acute or chronic stages of disease or even a stage that is clinically asymptomatic. In the latter situation the bacteria have the potential to resume growth, resulting in active disease, after several decades of dormancy resulting in active disease. This asymptomatic infection or latent stage is a long-term hidden threat to the host. Moreover, in the persistent stage mycobacteria reside in granulomas, which are organized collections of differentiated macrophages and other cell types. One important question is how mycobacteria survive within the granulomas for such a long time. It has been hypothesized that the bacteria remain in a dormant nonreplicative (or low level of replication) state at the centre of the granuloma or that the load of bacteria is kept constant through a dynamic equilibrium between killing by the immune system and bacterial replication/growth (Monack et al. 2004; Russell 2007).

Transition into dormancy and maintenance of the passive state until an appropriate signal(s) activates the vegetative, virulent state is one of the remarkable attributes of mycobacterial pathogens. As this entails temporary cessation of growth and cell division and their restart, the controls of bacterial growth, chromosome duplication, segregation and cell division must be clearly understood at the basic level for any meaningful insight into mycobacterial dormancy and virulence. It was during our investigations into the stages of growth, the basic cell cycle mechanisms and their controls in M. marinum, that we came upon the spore-forming ability of mycobacterial strains (Ghosh et al. 2009). We have continued those studies into the assembly and execution mechanisms of the cell division machinery in $M$. marinum and more recently also in M. smegmatis. In the present article, we will first briefly describe our current understanding of the division site selection process in bacterial model organisms. In view of our discovery that mycobacteria are capable of forming spores, we will then examine how mycobacteria might modify the division-site selection process to suit their own structural and proliferation requirements. We will also discuss the recently published criticism of our finding (Traag et al. 2010).

Growth and cell division

Most rod-shaped bacteria we know about grow along their axis and divide by binary fission. Cell division occurs by formation of a division septum at the midcell region after chromosome replication has been completed and the two daughter chromosomes have segregated into two halves of the cell (Harry 2001; Errington et al. 2003; Trevors 2004). The precise placement of the division site in coordination with growth, replication and segregation is critically important for propagation and all bacteria must have evolved elaborate division site selection systems appropriate for the growth and division schedule specific for their species (Goehring and Beckwith 
2005). Most of our understanding of division-site selection systems has been acquired from investigations into the growth and division mechanisms of the model gram-negative and gram-positive organisms Escherichia coli and Bacillus subtilis, respectively (Harry 2001; Errington et al. 2003; Lutkenhaus 2007; Adams and Errington 2009). The midcell placement of the FtsZ ring, the nucleating site for the division machinery (or divisome) in these cells is ensured by a combination of negative control systems. The MinCDE (or MinCDDivIVA) proteins prevent the Z-ring formation and subsequent divisome assembly at the cell poles. While the nuclear occlusion factors Noc and Slm prevent polymerization of FtsZ over the nucleoids; the nucleoid-free midcell region is thus the only zone available for FtsZ ring formation, the nucleation site for divisome assembly (Margolin 2001; Lutkenhaus 2007; Errington et al. 2003; Rothfield et al. 2005; Bernhardt and de Boer 2005; $\mathrm{Wu}$ and Errington 2004; Wu et al. 2009). Mycobacteria, however, possess uniquely complex cell walls that offer additional challenges to cell division requiring specialized mechanisms in addition to the general problems of coordination with growth and chromosome segregation (Hett and Rubin 2008). Also, as will be discussed below, mycobacteria apparently lack some key cell division proteins such as MinCDE, ZipA and ZapA that are involved in division site selection.

\section{Symmetric cell division}

Both in E. coli and B. subtilis, the cell division is orchestrated by FtsZ, a small prokaryotic cytoskeletal protein analog of eukaryotic tubulin, which polymerizes as a ring at a preselected site acting as a scaffold for assembly of the division machinery (Dajkovic and Lutkenhaus 2006; Barák and Wilkinson 2007). The Z-ring recruits all the downstream components of the divisome and participates in the complete division process. FtsZ is almost universally conserved and has also been identified in M. tuberculosis as one of the major cytoskeletal organizers of the mycobacterial divisome (Hett and Rubin 2008; Dziadek et al. 2003; Chen et al. 2007).

The spatial regulation of Z-ring formation at the midcell in E. coli and B. subtilis is enforced by two negative regulators: the Min and the nucleoid occlusion systems. In E. coli the Min system comprises the
MinC and MinD proteins that are responsible for elimination of the possibility of division at the cell pole. MinC inhibits FtsZ ring formation while MinD, a membrane-associated ATPase, functions as an activator for making the FtsZ ring. Visualization of the interior of live cells using fluorescence-tagged proteins has revealed that the MinCD complex undergoes pole-to-pole oscillation with a periodicity of 10-20 s along a spiral trajectory distinct from the spiral of the cytoskeletal shape-determinant MreB protein (Rothfield et al. 2005; Lutkenhaus 2007). The remarkable oscillation of the MinCD complex is driven by the cyclic association of MinD-ATP with the membrane, ATP hydrolysis by MinE and release of MinD-ADP and MinE into the cytoplasm. The FtsZ-inhibitor MinC forms a complex with MinD and co-oscillates with it such that its time-integrated concentration is the lowest at the midcell region and highest at the cell poles (see Margolin 2001; Barák and Wilkinson 2007; Lutkenhaus 2007). On the other hand, B. subtilis lacks MinE and does not exhibit MinCD oscillation. DivIVA, a protein without any similarity to MinE, controls MinCD by preventing FtsZ ring formation at the cell poles. DivIVA, localized at the cell poles, recruits MinCD by binding directly with MinD creating a pole-to-midcell concentration gradient of MinC. It has been demonstrated recently that the affinity of DivIVA for the poles is dictated by curvature of the membrane at the poles alone. It is not affected by any of the known cytoskeletal proteins (Lenarcic et al. 2009; Ramamurthi and Losick 2009). The primary role of MinCD in vegetatively growing $B$. subtilis is the prevention of Z-ring formation at the poles; nuclear occlusion ensures the midcell positioning of the division site.

Asymmetric cell division

There are special circumstances that drive B. subtilis and some Actinomycetes into sporulation as a survival strategy under extreme stress. In the case of B. subtilis the first morphological step after commitment to sporulation is formation of polar septa eventually leading to asymmetric cell division (Errington 2003; Errington et al. 2003; Hilbert and Piggot 2004). The division site is shifted from midcell to a position close to the cell poles. The septum is still formed by recruiting divisome components with a Z-ring as the nucleation center but its ultrastructure is altered in 
preparation of the downstream events that include conjugational uptake of one of the chromosomes after segregation and engulfment into mother cell. The genetics and physiology of this ordered series of complex events are only recently being unravelled. Starvation and crowding have emerged as the main but not the only stimulus for sporulation. The transcriptional regulator Spo0A is considered to be the master regulator for the switch from vegetative growth to sporulation controlling about $10 \%$ of all B. subtilis genes involved in the formation of spores. Spo0A expression is transcriptionally controlled and its activity is regulated by phosphorylation through several kinases in response to environmental stimuli and/or changes. Another component of the regulatory switch for sporulation is the stationary-phase sigma factor $\sigma^{\mathrm{H}}$ that combines with RNA polymerase to control the expression of more than 87 genes through 49 promoters (Britton et al. 2002). In addition to these positive transcription factors there are several negative regulators that keep sporulation suppressors under control (Ireton et al. 1994). Once the cell is committed to sporulation, a combination of increased FtsZ level and the expression of SpoIIIE cause disassembly of the medial Z-ring which now spirals out towards the poles (Ben-Yehuda et al. 2003). It is not clear how this combination of events overcomes the blockage of Z-ring formation near the pole caused by the Min system nor how the nuclear occlusion is bypassed.

\section{Division site selection in mycobacteria}

Unlike other gram-positive bacteria mycobacterial cell walls are not composed of a simple peptidoglycan network surrounding the membrane layer. Instead they comprise complex outer layers of arabinogalactan surrounding the peptidoglycan sacculus; the arabinogalactan layer itself acts as a scaffold-anchoring long-chain mycolic acids. This complex layered cell wall profoundly influences growth, survival under stress, pathogenicity and antibiotic resistance of mycobacterial species. Unlike other rod-shaped bacteria such as $B$. subtilis whose growth occurs by lateral intercalation of newly synthesized peptidoglycan along the helical MreB cytoskeleton, mycobacterial species of similar shape display a more flexible mode of apical growth where nascent peptidoglycan precursors are added exclusively at cell poles (Letek et al. 2008a, b; Thanky et al. 2007). (Mycobacteria appears to lack the helical MreB cytoskeleton since no MreB or MreB-analog have yet been identified.) Furthermore, when the cells' growth by polar extension, indicated by the presence of nascent peptidoglycan, has reached its limit of growth, building of the cell wall is shifted to the potential division site already marked by the FtsZ ring leading to the formation of the typical V-shape of dividing mycobacteria (Thanky et al. 2007; Singh et al. unpublished data; see also Lack and Tanner 1953; Dahl 2004). The mechanisms of division-site selection for formation of the Z-ring and subsequent recruitment of divisome components in mycobacteria remains to be elucidated. Neither the Min system nor the nucleoid occlusion mechanism are present in mycobacterial genome (no homologue systems have yet been identified). However, in the actinomycete Corynebacterium glutamicum, which also lacks MreB and MinCD, it was demonstrated that the FtsZ ring could assemble overlapping nucleoids even before they segregated, thereby confirming the absence of any nucleoid occlusion activity (Ramos et al. 2005).

In the absence of the spatial regulation by the Min system, DivIVA (or its analog Wag31) loses its role in septal site determination as in B. subtilis. Instead it operates more as a growth marker at the poles and is active in recruiting the cell wall synthesis machinery (Flärdh 2003a, b; Kang et al. 2005). Wag31 has also been found to bind PBP3 (FtsI), a transpeptidase required for peptidoglycan synthesis at the septum of dividing rod-shaped bacteria such as mycobacteria (Mukherjee et al. 2009). Thus recruitment of PBP3 might be needed for cell wall synthesis at growing poles as well as at the division site in mycobacteria (Datta et al. 2006; Scherr and Nguyen 2009). DivIVA forms higher-order homologs through its coiled coil domains. These have an affinity for curved membrane structures such that cell poles and division sites provide the topology that attracts DivIVA or Wag31 (Datta et al. 2006; Scherr and Nguyen 2009). Two serine/threonine protein kinases (PknA and $\mathrm{PknB}$ ) are involved in Wag31 regulation in mycobacteria and they have also been implicated in controlling mycobacterial growth and shape (Kang et al. 2005). Overexpression of Wag31 is known to cause local outgrowth converting the rod-shaped cells into enlarged, bulging bowling pins (Nguyen et al. 2007), an indication that there has been a loss of regulation of growth and shape. 


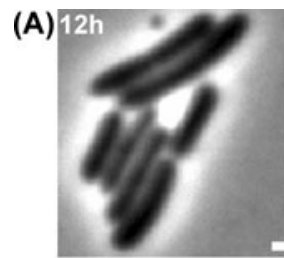

(D)

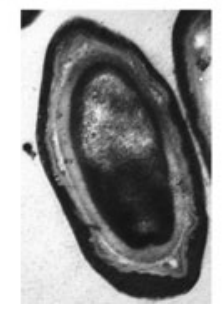

(E)

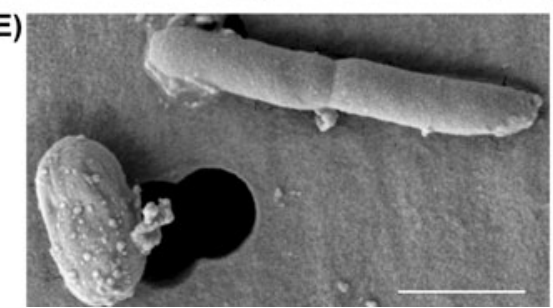

(B)

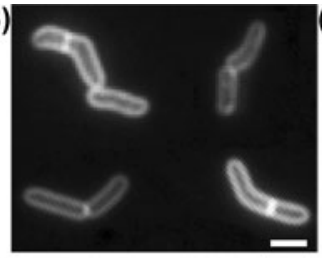

(F)

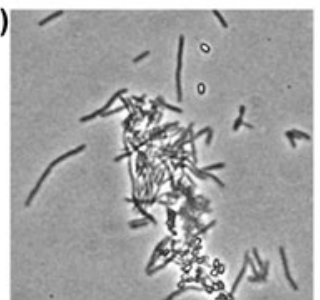

$(\mathrm{C})$

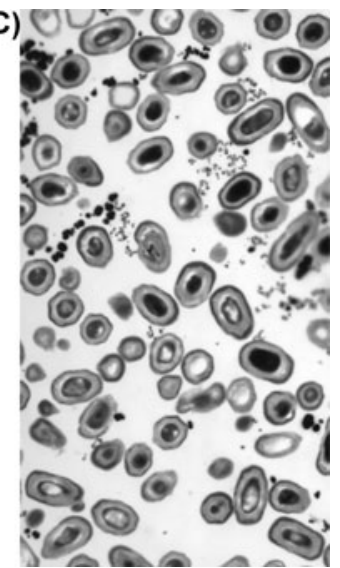

Fig. 1 Mycobacterium marinum spores. a Phase contrast micrograph of vegetative cells, $12 \mathrm{~h}$; endospore, 5d; and spores, 2w. b FM4-64 (membrane dye) stained vegetative cells showing asymmetrical cell division. c Transmission electron micrograph showing the morphological diversity of spores; magnification $\times 2,000$. d Transmission electron micrograph

Analysis of a large number of $M$. marinum and $M$. smegmatis cells undergoing division during steady growth showed that the division-site placement in mycobacteria is not necessarily at midcell (Fig. 1b). This is consistent with the absence of spatial regulation by Min system in mycobacteria. However, the FtsZ ring is still the determinant in establishing division site as previously reported (Dziadek et al. 2003; Chen et al. 2007). Despite either the asymmetric or random selection of the division site, the completion of division of mycobacteria produces predominantly normal sized cells with an intact genome content (in the absence of any nucleoidocclusion function). Thus mycobacteria must have some, as yet undiscovered, compensatory mechanism for correcting the lack of spatial regulation in division site placement such that newborn cells are not too unequal (Singh et al. in preparation). Recently, asymmetric/polar division was shown to occur in M. tuberculosis cells when partition protein ParB was overexpressed from an acetamide inducible promoter (Maloney et al. 2009) yielding nucleoid-free cells. This was different from the randomized division site during normal divisions in wild type $M$. marinum and M. smegmatis where production of nucleoid-free cells were rare possibly due to compensatory asymmetric growth at poles and chromosome translocations through the division site prior to cell division (Singh et al. in preparation). In view of endosporulation we
(TEM) of a mature spore; magnification $\times 60,000$. e Scanning electron micrograph (SEM) showing mature spore and vegetative cell. f Malachite green staining for spores, spores appears green. (Space bar $=1 \mu \mathrm{m}$ ). For further details see Ghosh et al. (2009)

emphasize that asymmetric septum formation is in keeping with the possibility that mycobacteria could enter a sporulation pathway if and/or when necessary (Ghosh et al. 2009) without any major switch in division site selection.

\section{Sporulation in mycobacteria}

We recently reported that spore like particles appeared in old cultures of $M$. marinum which disappeared during exponential growth and reappeared in the same culture late into the stationary phase (Ghosh et al. 2009). These particles possessed physical, biochemical, morphological and cell biological properties associated with spores and retained the genomic/genetic identity of M. marinum. For example we could demonstrate the presence of dipicolinic acid in old cultures, a biochemical hallmark of bacterial endospores (Church and Halvorson 1959; Paidhungat et al. 2000). When subjected to a classical, differential spore-staining protocol, the spore particles retained the malachite stain and appeared green while vegetative cells did not. Moreover, transmission electron microscopic (TEM) images showed that the structure of the M. marinum spore particles are morphologically similar to Bacillus spp. endospore (Fig. 1). Using bioinformatics to compare the mycobacterial genome with those of B. subtilis and Streptomyces coelicolor, we were also 
Table 1 Examples of signature sporulation genes from B. subtilis and their poor orthologs in M. marinum along with their general functions in non-sporulating bacteria

\begin{tabular}{lll}
\hline Orthologue & Sporulation function in B. subtilis & General function \\
\hline SpoVK, SpoIIIE & Maturation of spores and DNA translocase & $\begin{array}{c}\text { Widespread ATPases involved in many other } \\
\text { functions in non-sporulating bacteria }\end{array}$ \\
CotSA & Spore coat associated protein & Glycosyltransferase \\
SpoVE, Soj & Spore cortex synthesis, centromere-like function & Universal cell division proteins \\
SigF & Sigma factor controlling sporulation genes & Sigma factor \\
\hline
\end{tabular}

able to identify genes encoding putative orthologs (some are shown in Table 1) involved in mycobacterial sporulation. The expression profiles of some of these genes seem to suggest that they play a role in the sporulation pathway i.e. they increase their expression when the cells grow older (Ghosh et al. 2009). However, putative orthologues for some of the genes that play key roles in B. subtilis sporulation (Hilbert and Piggot 2004), e.g. spoIVA and spoIIIG (encoding the $\sigma^{\mathrm{G}}$ sigma factor), have not yet been identified (see also next section).

We also found that old cultures of M. bovis bacillus Calmette-Guérin seemed to form particles similar to M. marinum spores. Hence, we concluded that sporulation is not unique for M. marinum. Rather it is likely that sporulation is a more general feature and survival strategy among mycobacteria (Ghosh et al. 2009).

Consistent with their ability to form spores, mycobacteria might be expected to establish divisomes with a certain degree of randomness yielding daughter cells of unequal size as they do not have any mechanisms for division site selection around midcell (see above) with any degree of precision. Examination of a large number of cells in the process of undergoing division showed frequent establishment of the FtsZ-ring and/or peptidoglycan wall formed off-center and away from the midcell position (Singh et al. manuscript in preparation). Conceivably a small fraction of cells with asymmetric FtsZ-ring formation can proceed to form spores under as yet unknown, special circumstances.

Do mycobacteria sporulate?

Our finding that mycobacterial species can form spores faced extensive scrutiny by reviewers already before its acceptance for publication (Ghosh et al. 2009) and has met with considerable skepticism from several experts in the fields of sporulation and mycobacterial genetics/physiology after it was published. One of the main concerns was the absence of reliable reports of mycobacterial spores' existence despite the long history of extensive research on this organism. In fact, presence of spore-like particles in old mycobacterial cultures has been reported in the past but most of them could not be confirmed by other laboratories and were often declared to be artifacts commonly seen in the slow growing cultures of mycobacteria (see e.g. Lack and Tanner 1953; Brieger et al. 1954; Brieger and Glaubert 1956; Csillag 1961, 1963, 1964, 1970; Hilson 1965; and references in these). Another reasoning has been that endospore formation requires a unique set of proteins-synthesis of which is regulated by environmental and metabolic signals. Such an elaborately specialized phenomenon involving 150-200 gene functions orchestrated in highly precise spatio-temporal coordination would have to be conserved through evolution after its emergence; consequently, all endosporulating organisms would be expected to share a large number of orthologs or homologs in their sporulation pathway as the gram positive bacteria with low GC-content genomes classified as firmicutes do.

Recently, Traag et al. (2010) have published a paper challenging the validity and interpretation of our data showing that ageing cultures of M. marinum grown on plates at $30^{\circ} \mathrm{C}$ form endospores (Ghosh et al. 2009). Their critique rests on three key arguments that briefly can be summarized as follows. First, their independent blast and psi-blast searches against 15 mycobacterial and 18 streptomyces genomes failed to reveal any ortholog of the signature genes for endospore formation. Traag et al. (2010) also criticized the choice of the orthologs cited by Ghosh et al. (2009) to be diagnostic for endospore formation since these are also present in many nonendospore forming bacteria. Significant in their 
absence were the genes of the small, acid-soluble spore proteins (SASP) family of proteins dedicated to protecting the integrity of DNA within spores and the SpoVF operon, essential for dipicolinic acid synthesis (see e.g. Paidhungat et al. 2000; Setlow 2007; and references therein). Second, the spore and endospore images in Ghosh et al. (2009), in particular the transmission electron microscopic images, were remarkably similar to those of $B$. subtilis which is highly unlikely unless due to contamination with B. subtilis (Traag et al. 2010). Third, Traag et al. (2010) failed to detect the presence of spores or evidence of endosporulation either by microscopy or through heat resistance in laboratory cultures or from infected frogs chronically infected with M. marinum. Moreover, no spores were seen even when they used our published protocol for growing the cells obtained from our laboratory.

In summary, they took our results to be one of the several unfortunate cases of contamination of the slow growing mycobacteria with $B$. subtilis and wondered about the reproducibility of the sporulation data from a fresh culture in the hands of other workers. Below we respond to their three key arguments; but before that let us assert that several members of our laboratory have since reproduced the presence of spore-like particles independently in several different isolates of $M$. marinum strains.

As far as the bioinformatic criticism is concerned, it should be pointed out that our conclusion about endospore formation was neither derived from, nor did it depend on the discovery of orthologs of sporulation genes in mycobacterial genome-but relied on direct empirical observations of spores and establishment of spore-like properties which stand with or without bioinformatic support. Search for orthologs was prompted by the observational discovery itself and the ones found were published along with the "Forward Expect Values" that indicated their homology (see Table S1 in Ghosh et al. 2009) without assigning any function to these putative orthologs. These data were presented as intriguing information but our claim for sporulation was never dependent upon them. In Table 1 we provide examples of signature sporulation genes from $B$. subtilis and their orthologs in $M$. marinum along with their general functions in non-sporulating bacteria. As noted none of these proteins are specific for sporulating bacteria while sporulation specific genes, such as Spo0A are notably absent from mycobacterial genomes although a weak Spo0A candidate was discussed. However, the question arises whether absence of homology guarantees the absence of proteins with similar structure and function. Partition genes $m u k B$ and $s m c$; or nucleoid occlusion genes slm and noc, though almost identical in structure and perform similar functions in $E$. coli and B. subtilis, respectively, could not be identified by blast searches. Thus, structurally similar proteins performing identical functions in bacteria do not have to be bioinformatically matching orthologs of each other. Furthermore, many "sporulation" proteins show widespread phylogenic distribution, and perform alternative functions in non-sporulating bacteria (Rigden and Galperin 2008). It is therefore conceivable that apparently "non-sporulating" proteins involved in division site selection, septum formation, chromosome translocation, etc. might be activated to participate in sporulation triggered by appropriate metabolic or environmental signal(s). There are examples of sporulating bacteria differing significantly in essential sporulation pathways (Stephenson and Lewis 2005). Alternatively there are phototrophic Firmicutes (Heliobacteria) that contain the full complement of genes for sporulation pathway in their genomes but show ambiguous sporulation patterns; some species of Heliobacteria have never been observed to sporulate under laboratory conditions (Kimble-long and Madigan 2001; Sattley et al. 2008). Regarding the question: How reliable are bioinformatic arguments for denying the presence, or guaranteeing the absence, of a biological phenomenon or pathway in an evolutionary context? The answer from Dr M. Galperin (personal communication) was: "Establishing the absence of homology can be done when respective proteins have known three-dimensional structures but becomes a very difficult task when their structures are not known."

Regarding similarity with $B$. subtilis spores we emphasize that $M$. marinum spores show variation in appearance (Fig. 1c).

The failure to reproduce spores from our samples following our published protocol is by far the most serious and worrisome point raised by Traag et al. (2010); but even in our laboratory spore production has not been uniformly efficient and numerous. We believe this is because we have not yet identified the metabolic or environmental signal that switches on sporulation in mycobacteria. Work is in progress 
addressing this issue and we have preliminary data that show increasing sporulation frequency by changing growth conditions (manuscript in preparation). We emphasize that we have produced spore like particles from the cultures that was sent to Traag et al. (2010) to work with. Moreover, Fig. 2 shows spore particles derived from old cultures of a M. marinum derivative carrying the GFP gene integrated into the chromosome at the L5 attB site using an integrative suicide plasmid and that had been grown in the presence of kanamycin. The spore particles from 1 to 2 months old culture showed GFP fluorescence and we did not detect any contamination.

Finally, let us point out some of our reasoning why we rejected the arguments of contamination in the M. marinum cultures from some sporulating bacterial strains such as B. subtilis in the original paper (Ghosh et al. 2009). (i) The kinetics of appearance of sporelike particles were more consistent with life cycle and generation times of the relatively slower growing
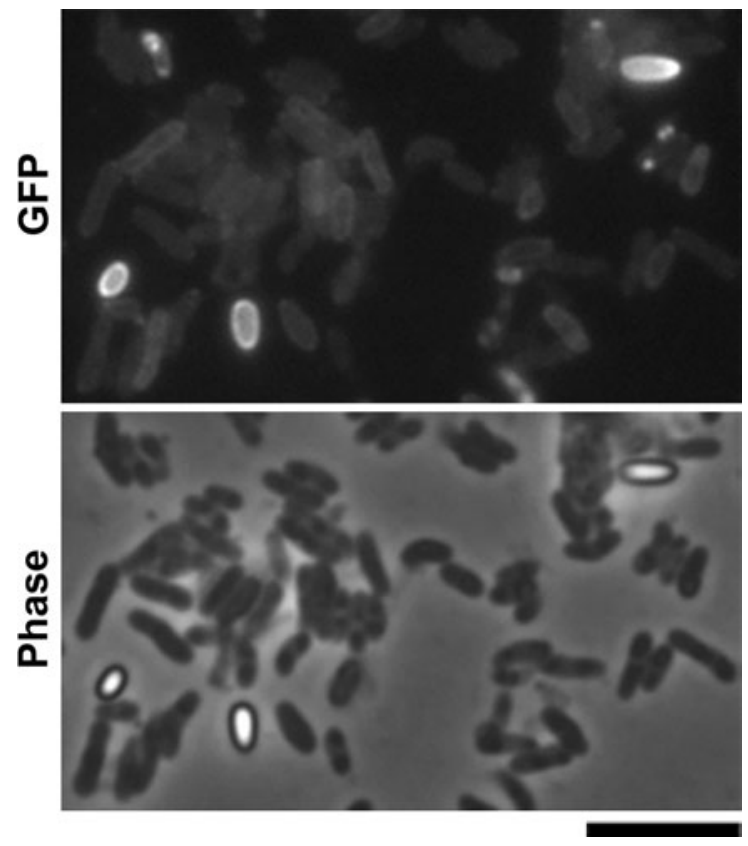

Fig. 2 Spores from an old culture (40 days) of the Mycobacterium marinum (strain T CCUG 20998 corresponding to ATCC 927) derivative M. marinum attB::gfp-Kan${ }^{\mathrm{R}}$ (GFP, green fluorescent protein gene linked to the $\mathrm{Kan}^{\mathrm{R}}$ gene integrated into the genome at the L5 attB site, the plasmid was kindly provided by Dr DG Ennis and Ms A. Mallick, Univ of Louisiana, Lafayette, USA) grown in the presence of kanamycin. The two images show phase contrast and fluorescence of the same field as indicated (space bar $=5 \mu \mathrm{m}$ )
M. marinum (168 h after inoculation; see Fig. 1 in Ghosh et al. 2009) than B. subtilis where spores in the latter case appear at a very high concentration in an overnight culture. (ii) The spore-like particles in the old cultures disappeared in the fresh inoculum and reappeared in the same culture late into stationary phase (Supplementary Fig. S1 in Ghosh et al. 2009). (iii) DNA content of the spore-like particles as estimated from the fluorescence profiles of flow cytometric histograms was consistent with the genome size of $M$. marinum, which is significantly larger than e.g. the $B$. subtilis genome (M. marinum $\approx 6.6 \mathrm{Mbp}$ vs. $\approx 4.2 \mathrm{Mbp}$ for B. subtilis; Kunst et al. 1997; Stinear et al. 2008). (iv) The presence of DPA in old cultures but not in fresh inocula of M. marinum provided a strong support to the idea of sporulation in mycobacteria. In addition to this our recent data where we have observed continuity of fluorescence due the presence of the $g f p$ gene and associated antibiotic resistance integrated into the mycobacterial genome (see Fig. 2) identifies the origin of spore particle as $M$. marinum. Combining all these together, we consider mycobacterial sporulation to have a strong empirical foundation despite poor bioinformatic support. In conclusion, our published and unpublished data suggest that $M$. marinum and likely also the $M$. bovis BCG strain form spores.

Sporulation in mycobacteria and spore formation in other bacteria

Sporulation has been extensively studied in Bacillus spp. (for reviews see e.g. Errington 2003; Hilbert and Piggot 2004). Bacillus spp. are low GC content Gram positive bacteria that belong to the Firmicutes. B. subtilis can also form cell types other than spores, for example motile, matrix-producing and competent cells. The underlying regulatory networks/factors that are involved in generating the different cell types have recently been reviewed (Lopez et al. 2009). Other Firmicutes such as Clostridia spp. (Paredes et al. 2005), some phototropic heliobacteria (KimbleLong and Madigan 2001) and the hydrogenogen Carboxydothermus hydrogenoformans Z-2901 (Wu et al. 2005) also form spores.

The Firmicutes form spores via an endosporulation pathway and sporulation depends on an array of events that depend on the expression and function of specific gene products. Analysis of the 
C. hydrogenoformans Z-2901 genome revealed that this organism appears to lack many of the genes involved in sporulation in e.g. B. subtilis (Wu et al. 2005). Moreover, in the case of the phototrophic heliobacteria the data suggest that these bacteria form spores at a low frequency (Kimble-Long and Madigan 2001; see also above).

The filamentous bacterium Streptomyces, which is an actinomycete, also produces spores. However, Streptomyces spp. produce spores on aerial hyphae. Compared to, for example B. subtilis spores, those of Streptomyces are less resistant (Flärdh and Buttner 2009). In a recent review Scherr and Nguyen (2009) discussed the similarities and differences between Mycobacterium and Streptomyces (Scherr and Nguyen 2009). Other actinomycetes bacteria produce non-motile spores without forming aerial hyphaes (Asano and Kawamoto 1986; Ara and Kudo 2006). For example Salinispora gen. nov., which belongs to a marine actinomycetes produce substrate hyphae carrying either single spores or cluster of spores. The diameter of these spores is in the range of $0.8-3.8 \mu \mathrm{m}$ (Maldonado et al. 2005). Another actinomycetes, the Nocardia spp., also appear to form spores (Bradley 1959; Brown-Elliott et al. 2006) while the actinomycetes Rhodococcus spp. show variations in cell morphology when grown under different growth conditions (Larkin et al. 2006 and references therein). However, none of the Rhodococcus spp. have been demonstrated to form spores and hence it would perhaps be of interest to investigate whether this is the case or not. In this context it is interesting to note that Mycobacterium and some Nocardia spp., e.g. strains of $N$. farcinica, as well as Rhodococcus spp. have properties in common (Goodfellow and Minnikin 1981; Zhi et al. 2009).

Among the Gram negative $\delta$-proteobacteria myxobacteria, where Myxobacteria xanthus is the best studied, starvation for phosphate or carbon can initiate formation of fruiting bodies (for recent reviews see Kroos 2007; Kaiser 2006). Within these bodies spores are subsequently generated. Comparing the regulatory networks leading to the production of spores in $M$. xanthus and B. subtilis reveals that they have different sporulation strategies. In the latter, a cascade of different sigma factors are involved, whereas this does not appear to be the case for M. xanthus. In $M$. xanthus the regulatory network appears to encompass a cascade of transcription factors that become phosphorylated, most likely in response to different signals and/or by binding to signal molecules (Kroos 2007). Interestingly, a natural isolate of B. subtilis has been demonstrated to form fruiting-body like structures containing spores, although this has not yet ever been observed in laboratory cultures of B. subtilis (Branda et al. 2001). This raises the question which genes are involved in generating fruiting bodies in B. subtilis. Perhaps they have been lost or "silenced" upon cultivation in the laboratory under controlled conditions.

Recently Girija et al. (2009) described a new Rhodobacter species, Rhodobacter johrii sp. nov. Interestingly this Gram-negative bacteria forms spores apparently via an endosporulation pathway. This is in contrast to what is known for this group of bacteria and it is important to identify the genes that are involved in spore formation in $R$. johrii sp. nov. The controversial observation that spore particles, spore-like bodies or mycococci form (a coccoid form in mycobacterial isolates) exist in Mycobacterium cultures has, as emphasized above, been discussed extensively in the early literature (see e.g. Lack and Tanner 1953; Brieger et al. 1954; Brieger and Glaubert 1956; Csillag 1961, 1963, 1964, 1970; Hilson 1965; and references in these). Our finding that mycobacteria indeed can form spores therefore seems to confirm these previously reported observations. In general bacteria have the capacity to adapt to various environmental conditions and can differentiate into different cell types (see e.g. Lopez et al. 2009). Together with the discussion above, it is therefore worth emphasizing that frequent subcultivation under laboratory conditions might select for specific types of growth that suppress formation of spores. Hence, with respect to mycobacterial growth, it is important to study the way they adapt to different environments. This is of particular importance if we are to find new strategies to detect, treat and prevent infections caused by the mycobacteria. Perhaps the adopted and standardized cultivation conditions in the laboratory has lead to a bias in our understanding of mycobacteria.

Sporulation in mycobacteria and possible clinical implications

Our finding, that $M$. marinum and seemingly also M. bovis BCG sporulate in late stationary phase 
(Ghosh et al. 2009), raises the interesting possibility that their ability to persist for a long time inside the host, may be due to the ability of mycobacteria to sporulate or enter into a spore-like stage. Thus, this hitherto uncharacterized phase of mycobacterial life style could be of critical importance for their pathogenicity, persistence and transmission. Important future questions are therefore to study whether other mycobacteria e.g. M. tuberculosis, also sporulate. Assuming that this is the case it is not unreasonable that the spores are subjected to phagocytosis by macrophages, as are Bacillus anthracis spores. Hence, another important question is whether mycobacteria spores enter macrophages and are degraded or if they reside in a dormant non-replicative state in the phagosome or elsewhere in the host. In the case of $B$. anthracis, spore germination in phagocytic cells is a key step in the pathogenic cycle (Henriques and Moran 2007). A third question is whether mycobacterial spore particles are involved in the transmission of pathogenic mycobacteria. For example, if $M$. ulcerans the causative agent of Buruli ulcer and a close relative of M. marinum (Stinear et al. 2000; Chemal et al. 2002), form spores, then these particles could be instrumental for the transmission of the bacteria. Likewise, mycobacterial spore particles might also be transmitted via our food in spite of sterilization protocols. In this context heat inactivation studies suggested that M. avium subsp. paratuberculosis can survive pasteurization if present in raw milk (Foddai et al. 2010). Hence the question of whether other mycobacteria form spores is an important one that warrants continued study.

Acknowledgements First we would like to express our gratitude to Dr DG Ennis and Ms A. Mallick (Univ of Louisiana, Lafayette, USA) for providing us with the unpublished plasmid carrying the gene encoding the GFP protein that was used to construct the M. marinum strain used in Fig. 2. We thank Ms T. Bergfors for critical reading of the manuscript. This work was supported by grants from the Swedish Foundation for Strategic Research, SIDA/SAREC, the Swedish Research Council for Environment, Agricultural Sciences, and Spatial Planning (FORMAS), the Carl Tryggers Foundation and the Söderberg Foundations.

Open Access This article is distributed under the terms of the Creative Commons Attribution Noncommercial License which permits any noncommercial use, distribution, and reproduction in any medium, provided the original author(s) and source are credited.

\section{References}

Adams DW, Errington J (2009) Bacterial cell division: assembly, maintenance and disassembly of the $\mathrm{Z}$ ring. Nat Rev Microbiol 7:642-653

Ara I, Kudo T (2006) Three novel species of the genus Catellatospora, Catellatospora chokoriensis sp. nov., Catellatospora coxensis sp. nov. and Catellatospora bangladeshensis sp. nov., and transfer of Catellatospora citrea subsp. methionotrophica Asano and Kawamoto 1988 to Catellatospora methionotrophica sp. nov., comb. nov. Int J Syst Evol Microbiol 56:393-400

Asano K, Kawamoto I (1986) Catellatospora, a new genus of the Actinomycetales. Int J Syst Bacteriol 36:512-517

Barák I, Wilkinson AJ (2007) Division site recognition in Escherichia coli and Bacillus subtilis. FEMS Microbiol Rev 31:311-326

Ben-Yehuda S, Rudner DZ, Losick R (2003) Assembly of the SpoIIIE DNA translocase depends on chromosome trapping in Bacillus subtilis. Curr Biol 13:2196-2200

Bernhardt TG, de Boer PA (2005) SlmA, a nucleoid-associated, FtsZ binding protein required for blocking septal ring assembly over chromosomes in E. coli. Mol Cell 18:555-564

Bradley SG (1959) Sporulation by some strains of Nocardiae and Streptomycetes. Appl Microbiol 7:89-93

Branda SS, Gonza'lez-Pastor JE, Ben-Yehuda S, Losick R, Kolter R (2001) Fruiting body formation by Bacillus subtilis. Proc Natl Acad Sci USA 98:11621-11626

Brieger EM, Glaubert AM (1956) Spore-like structures in the tubercle bacillus. Nature 178:544

Brieger EM, Cosslett VE, Glauert AM (1954) Reproductive changes in avian tubercle bacilli studied with the electron microscope. J Gen Microbiol 10:294-303

Britton RA, Eichenberger P, Gonzalez-Pastor JE, Fawcett P, Monson R, Losick R, Grossman AD (2002) Genomewide analysis of the stationary-phase sigma factor (sigma-H) regulon of Bacillus subtilis. J Bacteriol 184: 4881-4890

Brown-Elliott BA, Brown JM, Conville PS, Wallace RJ Jr (2006) Clinical and laboratory features of the Nocardia spp. based on current molecular taxonomy. Clin Microbiol Rev 19:259-282

Carter G, Wu M, Drummond DC, Bermudez LE (2003) Characterization of biofilm formation by clinical isolates of Mycobacterium avium. J Med Microbiol 52: $747-752$

Chacon O, Bermudez LE, Barletta RR (2004) Johne's disease, inflammatory bowel disease, and Mycobacterium paratuberculosis. Annu Rev Microbiol 58:329-363

Chemal K, Huys G, Laval F, Vincent V, Savage C, Gutierrez C, Laneelle MA, Swings J, Meyers WM, Daffe M, Portaels F (2002) Characterization of an unusual Mycobacterium: a possible missing ling between Mycobacterium marinum and Mycobacterium ulcerans. J Clin Microbiol 40:2370-2380

Chen Y, Anderson DE, Rajagoplan M, Erickson HP (2007) Assembly dynamics of Mycobacterium tuberculosis FtsZ. J Biol Chem 282:27736-27743 
Church BD, Halvorson H (1959) Dependence of the heat resistance of bacterial endospores on their dipicolinic acid content. Nature 183:124-125

Csillag A (1961) Morphological and biochemical features of 'Atypical' mycobacteria. J Gen Microbiol 24:261-272

Csillag A (1963) Cellular morphology of form 2 mycobacteria in slide culture. J Gen Microbiol 30:21-27

Csillag A (1964) Growth of a form 2 mycobacterium and various bacillus species on Löwenstein-Jensen medium. J Gen Microbiol 34:79-83

Csillag A (1970) A simple method to obtain the mycococcus form of Mycobacterium phlei. J Gen Microbiol 62:251-259

Dahl JL (2004) Electron microscopy analysis of Mycobacterium tuberculosis cell division. FEMS Microbiol Lett 240:15-20

Dajkovic A, Lutkenhaus J (2006) Z ring as executor of bacterial cell division. J Mol Microbiol Biotechnol 11:140-151

Datta P, Dasgupta A, Singh AK, Mukherjee P, Kundu M, Basu J (2006) Interaction between FtsW and penicillin-binding protein 3 (PBP3) directs PBP3 to mid-cell, controls cell septation and mediates the formation of a trimeric complex involving FtsZ, FtsW and PBP3 in mycobacteria. Mol Microbiol 62:1655-1673

Demangel C, Stinear TP, Cole ST (2009) Buruli ulcer: reductive evolution enhances pathogenicity of Mycobacterium ulcerans. Nat Rev Microbiol 7:50-60

Deretic V, Vergne I, Chua J, Master S, Singh SB, Fazio JA, Kyei G (2004) Endosomal membrane traffic: convergence point targeted by Mycobacterium tuberculosis and HIV. Cell Microbiol 6:999-1009

Dziadek J, Rutherford SA, Madiraju MV, Atkinson MA, Rajagopalan M (2003) Conditional expression of Mycobacterium smegmatis ftsZ, an essential cell division gene. Microbiology 149:1593-1603

Errington J (2003) Regulation of endospore formation in Bacillus subtilis. Nat Rev Microbiol 1:117-126

Errington J, Daniel RA, Scheffers DJ (2003) Cytokinesis in bacteria. Microbiol Mol Biol Rev 67:52-65

Flärdh K (2003a) Growth polarity and cell division in Streptomyces. Curr Opin Microbiol 6:564-571

Flärdh K (2003b) Essential role of DivIVA in polar growth and morphogenesis in Streptomyces coelicolor A3(2). Mol Microbiol 49:1523-1536

Flärdh K, Buttner MJ (2009) Streptomyces morphogenetics: dissecting differentiation in a filamentous bacterium. Nat Rev Microbiol 7:36-49

Flynn JL, Chan J (2003) Immune invasion by Mycobacterium tuberculosis: living with the enemy. Curr Opin Immunol 15:450-455

Flynn JL, Chan J (2005) What's good for the host is good for the bug. Trends Microbiol 13:99-102

Foddai A, Elliot CT, Grant IR (2010) Rapid assessment of the viability of Mycobacterium avium subsp. paratuberculosis cells after heat treatment, using an optimized phage amplification assay. Appl Environ Microbiol 76:17771782

Ghosh J, Larsson P, Singh B, Pettersson BM, Islam NM, Sarkar SN, Dasgupta S, Kirsebom LA (2009) Sporulation in mycobacteria. Proc Natl Acad Sci USA 106:10781-10786

Girija KR, Sasikala Ch, Ramana ChV, Spröer C, Takaichi S, Thiel V, Imhoff JF (2009) Rhodobacter johrii sp. nov., an endospore producing cryptic Rhodobacter species isolated from semi-arid tropical soils. Int J Syst Evol Microbiol Oct 23. doi:10.1099/ijs.0.011718

Glickman MS, Jacobs WR Jr (2001) Microbial pathogenesis of Mycobacterium tuberculosis: dawn of a discipline. Cell 104:477-485

Goehring NW, Beckwith J (2005) Diverse paths to midcell: assembly of the bacterial cell division machinery. Curr Biol 15:R514-R526

Goodfellow M, Minnikin DE (1981) The genera Nocardia and Rhodococcus. In: Starr MP, Stolp H, Trüper HG, Balows A, Schlegl HG (eds) The prokaryotes: a handbook on habitats, isolation and identification of bacteria. Springer, Berlin, pp 2017-2027

Greenstein RJ (2003) Is Crohn's disease caused by a mycobacterium? Comparisons with leprosy, tuberculosis, and Johne's disease. Lancet Infect Dis 3:507-514

Harry EJ (2001) Bacterial cell division: regulating Z-ring formation. Mol Microbiol 40:795-803

Henriques AO, Moran CP Jr (2007) Structure, assembly, and function of the spore surface layers. Annu Rev Microbiol 61:555-588

Hett EC, Rubin EJ (2008) Bacterial growth and cell division: a mycobacterial perspective. Microbiol Mol Biol Rev 72:126-156

Hilbert DW, Piggot PJ (2004) Compartmentalization of gene expression during Bacillus subtilis spore formation. Microbiol Mol Biol Rev 68:234-262

Hilson GRF (1965) Taxonomic characteristics of so-called 'Form 2 Mycobacteria'. J Gen Microbiol 39:407-421

Ireton K, Gunther NW 4th, Grossman AD (1994) spo0J is required for normal chromosome segregation as well as the initiation of sporulation in Bacillus subtilis. J Bacteriol 176:5320-5329

Kaiser D (2006) A microbial genetic journey. Annu Rev Microbiol 60:1-25

Kang CM, Abbott DW, Park ST, Dascher CC, Cantley LC, Husson RN (2005) The Mycobacterium tuberculosis serine/threonine kinases PknA and PknB; substrate identification and regulation of cell shape. Genes Dev 19: 1692-1704

Kimble-Long LK, Madigan MT (2001) Molecular evidence that the capacity for endosporulation is universal among phototropic heliobacteria. FEMS Microbiol Lett 199:191-195

Kroos L (2007) The Bacillus and Myxococcus developmental networks and their transcriptional regulators. Annu Rev Genet 41:13-39

Kunst $\mathrm{F}$ et al (1997) The complete genome sequence of the gram-positive bacterium Bacillus subtilis. Nature 390: 249-256

Lack CH, Tanner F (1953) The significance of pleomorphism in Mycobacterium tuberculosis var. hominis. J Gen Microbiol 8:18-26

Larkin MJ, Kulakov LA, Allen CCR (2006) Biodegradation by members of the genus Rhodococcus: biochemistry, physiology, and genetic adaptation. Adv Appl Microbiol 59:1-29

Lenarcic R, Halbedel S, Visser L, Shaw M, Wu LJ, Errington J, Marenduzzo D, Hamoen LW (2009) Localisation of DivIVA by targeting to negatively curved membranes. EMBO J 28:2272-2282 
Letek M, Ordónez E, Vaquera J, Margolin W, Flärdh K, Mateos LM, Gil JA (2008a) DivIVA is required for polar growth in the MreB-lacking rod-shaped actinomycete Corynebacterium glutamicum. J Bacteriol 190:3283-3292

Letek M, Fiuza M, Ordónez E, Villadangos AF, Ramos A, Mateos LM, Gil JA (2008b) Cell growth and cell division in the rod-shaped actinomycete Corynebacterium glutamicum. Antonie Van Leeuwenhoek 94:99-109

Lopez D, Vlamakis H, Kolter R (2009) Generation of multiple cell types in Bacillus subtilis. FEMS Microbiol Rev 33:152-163

Lutkenhaus J (2007) Assembly dynamics of the bacterial MinCDE system and spatial regulation of the $\mathrm{Z}$ ring. Annu Rev Biochem 76:539-562

Maldonado LA, Fenical W, Jensen PR, Kauffman CA, Mincer TJ, Ward AC, Bull AT Goodfellow M (2005) Salinispora arenicola gen. nov., sp. nov. and Salinispora tropica sp. nov., obligate marine actinomycetes belonging to the family Micromonosporaceae. Int J Syst Evol Microbiol 55:1759-1766

Maloney E, Madiraju M, Rajagopalan M (2009) Overproduction and localization of Mycobacterium tuberculosis ParA and ParB proteins. Tuberculosis 89:S65-S69

Margolin W (2001) Spatial regulation of cytokinesis in bacteria. Curr Opin Microbiol 4:647-652

Monack DM, Mueller A, Falkow S (2004) Persistent bacterial infections: the interface of the pathogen and the host immune system. Nat Rev Microbiol 2:747-765

Mukherjee P, Sureka K, Datta P, Hossain T, Barik S, Das KP, Kundu M, Basu J (2009) Novel role of Wag31 in protection of mycobacteria under oxidative stress. Mol Microbiol 73:103-119

Nguyen L, Pieters J (2005) The Trojan horse: survival tactics of pathogenic mycobacteria in macrophages. Trends Cell Biol 15:269-276

Nguyen L, Scherr N, Gatfield J, Walburger A, Pieters J, Thompson CJ (2007) Antigen 84, an effector of pleiomorphism in Mycobacterium smegmatis. J Bacteriol 189:7896-7910

Ojha A, Anand M, Bhatt A, Kremer L, Jacobs WR Jr, Hatfull GF (2005) GroEL1: a dedicated chaperone involved in mycolic acid biosynthesis during biofilm formation in mycobacteria. Cell 123:861-873

Paidhungat M, Setlow B, Driks A, Setlow P (2000) Characterization of spores of Bacillus subtilis which lack dipicolinic acid. J Bacteriol 182:5505-5512

Paredes CJ, Alsaker KV, Papoutsakis ET (2005) A comparative genomic view of clostridial sporulation and physiology. Nat Rev Microbiol 3:969-978

Primm TP, Lucero CA, Falkinham JO 3rd (2004) Health impacts of environmental mycobacteria. Clin Microbiol Rev 17:98-106

Ramakrishnan L (2004) Using Mycobacterium marinum and its hosts to study tuberculosis. Curr Sci 86:82-92

Ramamurthi KS, Losick R (2009) Negative membrane curvature as a cue for subcellular localization of a bacterial protein. Proc Natl Acad Sci USA 106:13541-13545

Ramos A, Letek M, Campelo AB, Vaquera J, Mateos LM, Gil JA (2005) Altered morphology produced by ftsZ expression in Corynebacterium glutamicum ATCC 13869. Microbiology 151:2563-2572
Rigden DJ, Galperin MY (2008) Sequence analysis of GerM and SpoVS, uncharacterized bacterial 'sporulation' proteins with widespread phylogenetic distribution. Bioinformatics 24:1793-1797

Rothfield L, Taghbalout A, Shih YL (2005) Spatial control of bacterial division-site placement. Nat Rev Microbiol 3:959-968

Russell DG (2007) Who puts the tubercle in tuberculosis? Nat Rev Microbiol 5:39-47

Sasaki S, Takeshita F, Okuda K, Ishii N (2001) Mycobacterium leprae and leprosy: a compendium. Microbiol Immunol 45:729-736

Sattley WM, Madigan MT et al (2008) The genome of Heliobacterium modesticaldum, a phototrophic representative of the firmicutes containing the simplest photosynthetic apparatus. J Bacteriol 190:4687-4696

Scherr N, Nguyen L (2009) Mycobacterium versus Streptomyces-we are different, we are the same. Curr Opin Microbiol 12:699-707

Setlow P (2007) I will survive: DNA protection in bacterial spores. Trends Microbiol 15:172-180

Stephenson K, Lewis RJ (2005) Molecular insights into the initiation of sporulation in Gram-positive bacteria: new technologies for an old phenomenon. FEMS Microbiol Rev 29:281-301

Stinear TP, Jenkin GA, Johnson PDR, Davies JK (2000) Comparative genetic analysis of Mycobacterium ulcerans and Mycobacterium marinum reveals evidence of recent divergence. J Bacteriol 182:6322-6330

Stinear TP et al (2008) Insights from the complete genome sequence of Mycobacterium marinum on the evolution of Mycobacterium tuberculosis. Genome Res 18:729-741

Thanky NR, Young DB, Robertson BD (2007) Unusual features of the cell cycle in mycobacteria: polar-restricted growth and the snapping-model of cell division. Tuberculosis 87:231-236

Traag BA, Driks A, Stragier P, Bitter W, Broussard G, Hatfull G, Chu F, Adams KN, Ramakrishnan L, Losick R (2010) Do mycobacteria produce endospores? Proc Natl Acad Sci USA 107:878-881

Trevors JT (2004) Evolution of cell division in bacteria. Theory Biosci 123:3-15

Uzoigwe JC, Khaitsa ML, Gibbs PS (2007) Epidemiological evidence for Mycobacterium avium subspecies paratuberculosis as a cause of Crohn's disease. Epidemiol Infect 135:1057-1068

Vaerewijck MJ, Huys G, Palomino JC, Swings J, Portaels F (2005) Mycobacteria in drinking water distribution systems: ecology and significance for human health. FEMS Microbiol Rev 29:911-934

Vergne I, Chua J, Singh SB, Deretic V (2004) Cell biology of Mycobacterium tuberculosis phagosome. Annu Rev Cell Dev Biol 20:367-394

Wayne LG, Sohaskey CD (2001) Nonreplicating persistence of Mycobacterium tuberculosis. Annu Rev Microbiol 5: 139-163

Wu LJ, Errington J (2004) Coordination of cell division and chromosome segregation by a nucleoid occlusion protein in Bacillus subtilis. Cell 117:915-925

Wu M, Ren Q, Durkin AS, Daugherty SC, Brinkac LM, Dodson RJ, Madupu R, Sullivan SA, Kolonay JF, Nelson 
WC, Tallon LJ, Jones KM, Ulrich LE, Gonzalez JM, Zhulin IB, Robb FT, Eisen JA (2005) Life in hot carbon monoxide: the complete genome sequence of Carboxydothermus hydrogenoformans Z-2901. PLoS Genet 1:563-574

Wu LJ, Ishikawa S, Kawai Y, Oshima T, Ogasawara N, Errington J (2009) Noc protein binds to specific DNA sequences to coordinate cell division with chromosome segregation. EMBO J 28:1940-1952
Zhi X-Y, Li W-J, Stackebrandt E (2009) An update of the structure and 16S rRNA gene sequence-based definition of higher ranks of the class Actinobacteria, with the proposal of two new suborders and four new families and emended descriptions of the existing higher taxa. Int $\mathbf{J}$ Syst Evol Microbiol 59:589-608 